\title{
DSS and ITS for intermodal freight transport: some European experiences
}

\author{
U. Sansone \\ DIIES-Dipartimento di ingegneria dell'Informazione, \\ delle Infrastrutture e dell'Energia Sostenibile, \\ Università degli Studi Mediterranea di Reggio Calabria, Italy
}

\begin{abstract}
The subject of this paper is the use of ITS (Intelligent Transport System) with the DSS (Decision Support System) for intermodal transport.

The types of ITS are classified with attention to specific mobility sequences for freight movements. Referential freight ITS are the CVO (Commercial Vehicle Operations). Then four management tools are presented: SAP-YARD, CroBIT, UirNet and Access. A classification is proposed in which the various types of ITS present in each DSS are highlighted.

Keywords: DSS, ITS, freight, intermodality, logistic.
\end{abstract}

\section{Introduction}

In freight transport there is a range of distances within which it is not uniquely determined how to make the transfer. In short distances the transfer is always made by road, while the long or very long intercontinental distances are covered by sea [1].

Freight transport is one of the most important issues of the European Union. From the documents of the European Commission emerges the following information [2]:

- on an international scale in both import and export for the year 2011, there were $2224.5 \times 10^{3}$ tons;

- on a national scale inside the EU-27 countries, for the year 2011, there were $3824 \times 10^{6}$ tons-km;

- on a local scale inside the EU-27 countries, for the year 2011, there were $97.34 \times 10^{6}$ tons-km. 
Over the past few decades, freight transport in tons-kilometers has followed very closely the evolution of the Gross Domestic Product (GDP) in the member states of the EU-27. In 2010, freight transport rate of growth was found to be $5.3 \%$ and the GDP rate of growth of $2 \%$ [3].

The European Union works towards decoupling the two growths and the reduction of the negative impacts of freight transport in terms of environmental, economic and social sustainability.

To improve freight transport, regarding the sustainability goal, the European Commission has highlighted the role of the ITS (Intelligent Transport System) in the "White Paper Roadmap to a Single European Transport Area" [4]. It is possible to see that the presence of an efficient transport system, for the functioning of the internal market and for the integration of the European Union in the global market, is of vital importance for the development of freight transport.

The European Commission's objectives, described in the White Paper of 2011 expiring in 2050, are [4]:

- absence of cars with a conventional power supply (petroleum);

- $40 \%$ increase in the use of sustainable low emission fuels in air transport, at least a $40 \%$ cut in emissions in shipments;

- $50 \%$ increase in use of rail or naval transport for intercity journeys for both passengers and freight.

In Italy, freight transport is mainly focused on road transport for a total of $175.7 \times 10^{6}$ tons-km (2010), compared to rail transport that has a total of $13.4 \times 10^{6}$ tons-km (2010) [5].

The important presence of road traffic in the economy of the country leads to negativity from the point of view of environmental $\left(\mathrm{CO}_{2}\right.$ emissions), economic (inadequate infrastructure compared to an ever-increasing flow), social sustainability (accessibility, security).

In Europe, the sum of the cost of logistics and transport has a weight equal to $16 \%$ of industrial production, while in Italy these costs weigh $20.5 \%$ [6].

The transport and logistics sector in Italy has a total turnover of 188 billion euro (Table 1). The use of ITS for reducing inefficiencies in logistics in Italy according to the new National Logistics Plan 2012-2020, pending approval from CIPE, is estimated at 40 billion euro [7].

Table 1: $\quad$ Turnover in transport and logistics $\left(1 \times 10^{9} € 2010\right)[6]$.

\begin{tabular}{lccc}
\hline Mode of transport & $\begin{array}{c}\text { Own } \\
\text { account }\end{array}$ & $\begin{array}{c}\text { On behalf of third } \\
\text { parties }\end{array}$ & Total \\
\hline Road & 48 & 35 & 83 \\
Sea & - & 12 & 12 \\
Air & - & 2 & 2 \\
Rail & - & 1 & 1 \\
\hline Total transport & 48 & 50 & 98 \\
Logistics without & 76 & 14 & 90 \\
transport & & & 188 \\
\hline Total logistics & 124 & 64 & \\
\hline
\end{tabular}


The factors that at different spatial scales determine the current conditions of modal preference are treated in many papers present in the literature. Some of the latest notes are mentioned, referring to them and the bibliographies contained for additional specifications: for the intercontinental [8] and [9], for the national [10, 11], for the local [12-14].

In this paper, attention is drawn to the intermodal transport, with its specific characteristics. Intermodal transport constitutes today the mode that provides the most overall sustainability. On the one hand, intermodal transport makes even greater use of ITS instruments; on the other, it has used the DSS to coordinate the various actors that interact.

Based on these considerations, a study is therefore useful that considers the real experiences in which ITS operate within DSS for intermodality.

Specifically in this paper, ITS are mentioned for freight transport, as well as being classified at an international level, and some of the DSS for freight that make use of ITS are used in Europe.

\section{ITS for freight transport}

The classification of ITS used is the European ones, organized by functional groups (Fig. 1) [15]:

- INVS, In-Vehicle Navigation System;

- ATPS, Advanced Public Transport Systems;

- CVO, Commercial Vehicle Operation;

- EMS, Emergency Management Systems.

The four groups refer to the most important mobility segments.

INVS is the group of ITS that supports private transport in all its elements. From the safety systems introduced in vehicles, to the traffic control systems.

ATPS is the group of ITS that supports mass transit, the organization of the fleets of vehicles and their control.

CVO is the group relative to the goods fleets in which it includes both the ITS for loading units, units for transport and for the handling units.

EMS is the group of ITS that operates throughout the emergency conditions affecting different systems of transport offer.

It's possible to note that the four groups are based upon three sub systems that link the manager-driver-vehicle:

- ATMS (Advanced Traffic Management Systems);

- AVCS (Advanced Vehicle Control Systems);

- ATIS (Advanced Traveller Information Systems).

The use of CVO allows the routes to be made easier and for there to be more reliable transfers in routes with less congestion, greater safety and better services. In this section the principal subsystems that make up the CVO are divided according to the scheme proposed. 


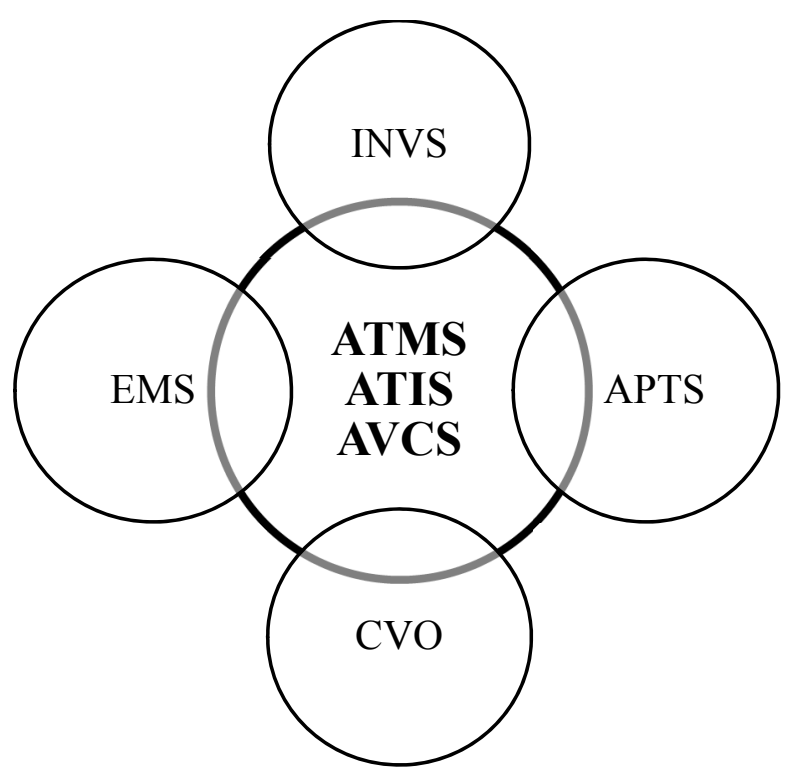

Figure 1: Functional partition of ITS systems.

\section{DSS for freight transport}

In this section some of the most important Decision Support System that make use of ITS subsystems are recalled. In Table 2 the main subsystems developed with their international acronyms are reported.

Table 2: $\quad$ CVO system division.

\begin{tabular}{cc}
\hline Systems & CVO \\
International acronyms \\
\hline Supply chain management & FFMS (Freight and Fleet Management Systems) \\
CVIS (Commercial Vehicle Information Systems \\
and Network)
\end{tabular}


The DSS regarding the intermodal freight transport considered are: SAPYARD, CroBIT, UIRNet, ACCESS.

For each DSS the main features are described and the ITS subsystems that they use are highlighted.

The DSS for the local domestic transport work on whether to assist the decisions about the vehicle and cargo units while travelling in modal systems, and for specific movements in intermodal nodes.

In relation to the movements within the intermodal nodes in Fig. 2, a synchronic summary graph is proposed and in Table 3 the main elements of the graph are described.

This graph can be considered as reference for the items relating to node decisions in the DSS discussed further.

\subsection{SAP-YARD pattern}

During the years 2008-2010 through the PIL-(Platform Integrated Logistics), an informative platform has been activated through which the Ferrovie dello Stato Group can offer a range of services for the vector of combined freight transport, road-rail, rail-road. The Program PIL was created in February of 2008 and has as its objective the development of ITS solutions in support of logistics services.

The main characteristics of the PIL programme parts are [16]:

- PIC MOVE (Shunting)

○ Objective: Management of composition / decomposition of convoys in railway yards;

- Operators: RFI and other private groups;

- Platform: PIC (Integrated Platform of Circulation).

- LMF, Logistic Management Framework (Integration)

○ Objective: Management of information exchange among all logistics operators;

- Operators: Trenitalia, TX Logistik, RFI, FSL-Italcontainer, Cemat, Terminali Italia;

- Platform: SAP.

- SAP-TM (Freight Transport)

- Objective: Management of distribution integrated logistics processes (platform, warehouse, rubberized);

○ Operators: FS_Logistica;

- Platform: SAP.

- SAP-TM (CombinedTransport)

○ Objective: Management of MTO (Multimodal Transport Operator) processes;

- Operators: FSL-Italcontainer, Cemat;

○ Platform: SAP.

- SAP-YARD (Handling)

○ Objective: Management of the processes in Terminal Container;

- Operators: Terminali Italia, FR Logistica;

○ Platform: SAP. 


\section{Pattern: Sap-Yard N N}

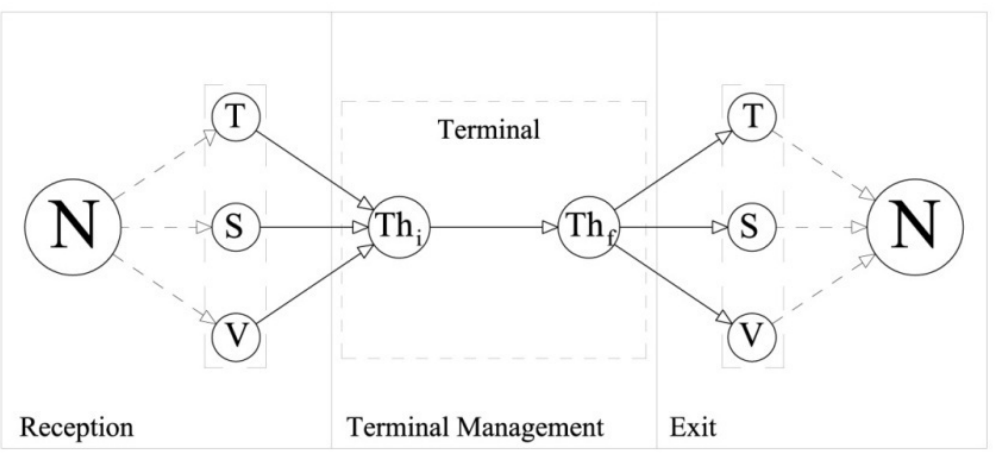

Node modal choice

Terminal node

Link spatial

Link temporal

Figure 2: Synchronic graph of intermodal node.

Table 3: Elements of graph description.

\begin{tabular}{cc}
\hline Description & Node \\
\hline $\mathrm{N}$ & Network \\
$\mathrm{T}, \mathrm{S}, \mathrm{V}$ & Mode transport (train/ship/vehicle) \\
$\mathrm{Th}_{\mathrm{s}} / \mathrm{Th}_{\mathrm{f}}$ & Terminal handling start/finish \\
\hline Description & Link \\
\hline $\mathrm{N}^{-} \mathrm{Th}_{\mathrm{s}}$ & Time input from the network to the terminal (check-in) \\
$\mathrm{Th}_{\mathrm{s}}-\mathrm{Th}_{\mathrm{f}}$ & Time spent in the terminal \\
$\mathrm{Th}_{\mathrm{f}}-\mathrm{N}$ & Time taken to exit the terminal (check-out) \\
\hline
\end{tabular}

In 2010 Almaviva S.p.A. (an Italian group consisting of Almaviva Tsf, 63\%, Telecom Italia, $13.5 \%$ engineering, $10 \%$ and Ansaldo STS, $13.5 \%$ ) was awarded the tender for the management of IT services, of infrastructure, data processing, management and development of software application and call center for the FS group [17].

The main purpose of this informative platform is to automate the logistics activities and to substantially reduce the operating time within an end-to-end chain. The reported system for the operational management of the terminal (Handling) is called SAP-YARD, the whole process is represented by the phase of the roadside entrance, the handling on the yard and the roadside exit.

The SAP-YARD pattern has the function of being the intermediary between the sender (customer) and the receiver (consignee), through the hardware and software interface, between hauler, Railway Enterprise (RFI) and Multimodal Transport Operator (MTO) with the manager of the node/goods center (terminal). The dialogue created between the terminal and the MTO is based on specialized 
technical activities (goods loading, unloading and transhipment with special equipment, insurance of goods, customs and administrative fulfilment) with also, by MTO, a role of coordination of all actors that cooperate in the realization of the transport (couriers; carriers; general stores).

The model SAP-YARD is composed of four submodels made of input and output variables connected to each other through their respective functions.

In parentheses there are the ITS-CVO systems developed in the specific subsystems:

- Sub-model "Acceptance vehicle" (DGMS-HMM);

- Sub-model "Management of the terminal" (FTM);

- Sub-model "Exit vehicle" (DGMS-HMM);

- Sub-model "Track \& Trace” (WIM).

The model SAP-YARD applies to a simple schematization (Network/Terminal-handling/Network) of connection between two networks through an intermodal exchange node. The graph of the pattern represented is applicable to all the modes of transport as SAP-YARD aims to support the terminal to connect the different modes, and it is represented in figure 2.

\subsection{Platform pattern UIRNet (Unione Interporti Riuniti-Network)}

The company UIRNet (Unioni Interporti Riuniti-Network) has the task of creating a computerized system of reference for the management of the national logistics network, NLP (National Logistic Platform). The NLP is intended to allow the interconnection of the nodes of modal interchange (Interporti) with the aim of improving efficiency and safety in logistics in Italy, as defined by the D.M. $\mathrm{n}^{\circ} 18 \mathrm{~T}$ dated 20 June 2005 and then underlined by Law 27 of 24 March 2012. In 2007, the Ministry of Transport signed a second agreement with the Company UIRNet for activities in the field of security, to be carried out within the structures of the intermodal logistics of first level [17].

The platform UIRNet provides services of a system to all the operators, becoming the platform of interconnection and management of the flow of data and processes related to it.

The logistics platform UIRNet is composed of two main patterns, the Smart Truck, which has a logic similar to the platform CroBIT, and deals with the network path at the entrance and from the exit of the terminal at the entrance in the network; Control Tower, which instead has a logic similar to SAP-YARD, and is responsible for the management of the movements within the terminal.

To do that, the National Logistics Platform is equipped with an open, interoperable and scalable infrastructure, divided in $[18,19]$ :

- Smart Truck offers the control of small fleets and enriches the fleet management services with tools that allow one to plan and manage the missions, to calculate the time of arrival and to manage the documentation, knowing in the real-time the state of viability and operability of destinations; ITS-CVO system used: FFMS.

- Control Tower, allows one to know in real time the incoming vehicles, investigate the status of a single vehicle on arrival (e.g., documentation 
status) and view the documentation relating to the means made available by the carriers, being able to verify it before their arrival.

ITS-CVO system used: WIM.

\subsection{CroBIT pattern (Cross-Border Information Technology)}

Between 1998 and 2002 the 5th Research and Technological Development Framework Programme operated; one of the objectives was the development of interoperability of European rail networks of freight transport. In 2003, a new research was produced to develop, test and evaluate real solutions for the integration of freight trains within the priority projects of the Trans European Rail Freight Network with particular regard to solutions using ICT (Information and Communication Technologies). One of these ICT systems is CroBIT

(Cross-Border Information Technology), an electronic platform used to provide an efficient data exchange through the development of effective system interfaces, so that rail operators can continue to use their existing data formats and protocols but incorporated in a more integrated end-to-end management, within the TEN-T (Trans European Network-Transport) [20, 21].

CroBIT system does not require specific input, as it is based on existing data from various users and is able to complete the information on the original expedition, through the addition of data received from various partners, such as reason codes for delays, plan to travel or arrival information and real time. CroBIT forms an essential bridge between matter and transport flows with the RU (Rail Undertakings) or the railway companies and the IM (Infrastructure Managers), representing the infrastructure managers. Initially, the flow of information (e.g. shipping documents) of the train/load was known only in the source nodes, intermediate and destination, but along the way there were no precise information on the state of the circulation. CroBIT's task is to fill this gap, providing on-line data about the location and status of the means of transport (e.g., wagon or container) of goods along its path (HR \& IM Layers).

CroBIT does not replace any of the operating systems of the freight train of the various operators or infrastructure, but instead, is able to interface with all stakeholders, customers, and carriers involved in the shipment.

ITS-CVO systems used are: FFMS-CVISN-FITM.

CroBIT deals with the tracking of the material stock in line with different managers so its use is not intermodal but monomodal, multi-user for train or monomodal mode complex.

\subsection{ACCESS pattern (Advanced Contact Center for the Enhancement of Short-sea Shipping)}

In December 2004, on the occasion of the announcement Marco Polo, RAM and Cons.A.R. for Italy, together with European partners in Spain and France presented a proposal called ACCESS (Advanced Contact Center for the Enhancement of Short-sea Shipping) for the development of a system based on a web portal with the aim of facilitating the trucking access to the Motorways of the Sea. This system foresees the activation of a data base able to manage, in a secure 
and protected way, the necessary information to facilitate the loading of trucks that carry goods (trucks, semi-trailer trucks/articulated vehicles, trailers, etc.) gradually extended to all the active lines in the Mediterranean sea. The main function of ACCESS is to oversimplify the transition from seaway transport to roadway transport by reducing the parking times of motor vehicles and ships, and therefore making maritime transport more accessible, affordable, efficient and competitive compared to the road within an intermodal cycle $[22,23]$.

The platform ACCESS provides a single point of internet access (one stop shopping) to the various services offered by shipping companies, to operators of road transport (carrier), to the Mediterranean Highways Network and to public authorities. Its use allows one to obtain various advantages in terms of cost and time containment required to carry out the procedures necessary for the full and optimal implementation of intermodality.

ITS-CVO systems used are: FFMS-CVISN-FITM-FTM.

The model ACCESS has the characteristic, similar to the structure of the model CroBIT, of monomodability of application to a generic network NetworkTerminal-Network, for the accuracy concerns the mode by ship [24].

\subsection{Comparison between models}

The presented DSS can be introduced in a matrix highlighting ITS subsystems for freight transport (CVO) that they have in common (Table 4), on the basis of the

Table 4: $\quad$ Matrix comparison between models DSS and CVO.

\begin{tabular}{|c|c|c|c|c|c|c|}
\hline \multicolumn{4}{|c|}{ Patterns for terminal } & \multicolumn{3}{|c|}{ Patterns for line } \\
\hline CVO & & $\begin{array}{l}\text { UIRNet } \\
\text { (CT) }\end{array}$ & $\begin{array}{l}\text { SAP- } \\
\text { YARD }\end{array}$ & $\begin{array}{l}\text { UIRNet } \\
\text { (ST) }\end{array}$ & ACCESS & CroBIT \\
\hline \multirow{2}{*}{$\begin{array}{l}\text { Supply chain } \\
\text { management }\end{array}$} & FFMS & & & $\mathrm{x}$ & $\mathrm{x}$ & $\mathrm{x}$ \\
\hline & CVISN & & & & $\mathrm{x}$ & $\mathrm{x}$ \\
\hline \multirow{5}{*}{ Tracking } & AVL & & & $\mathrm{x}$ & & \\
\hline & AVI & & & & & \\
\hline & AVM & & & $\mathrm{x}$ & & \\
\hline & AVC & & & & & \\
\hline & FITM & $\mathrm{x}$ & & & $\mathrm{x}$ & $\mathrm{x}$ \\
\hline Tracing & WIM & $\mathrm{x}$ & $\mathrm{x}$ & & & \\
\hline Dangerous & DGMS & $\mathrm{x}$ & $\mathrm{x}-\mathrm{VA}$ & & & \\
\hline $\begin{array}{c}\text { goods } \\
\text { management }\end{array}$ & HMM & & $\mathrm{x}-\mathrm{VA}$ & & & \\
\hline \multirow{2}{*}{ City logistic } & FDMS & & & & & \\
\hline & UFDC & & & & & \\
\hline $\begin{array}{c}\text { Terminal } \\
\text { management }\end{array}$ & FTM & & $\mathrm{x}-\mathrm{H}$ & & $\mathrm{x}$ & \\
\hline
\end{tabular}


classification proposed previously. As we said, it is possible to make a segmentation of DSS in function of the field of application: terminal and/or lines.

- DSS for the terminals:

- SAP-YARD;

○ UIRNet (Control Tower).

- $\quad$ DSS for the lines:

- CroBIT (railway);

- UIRNet (Smart Truck);

- ACCESS (sea).

\section{Acknowledgement}

Partially supported by Terminali Italia S.r.l. in the person of Ing. Olimpia Di Naro.

\section{References}

[1] Russo F., Sistemi di trasporto merci: Approcci quantitativi per il supporto alle decisioni di pianificazione strategica, tattica ed operativa a scala nazionale. Franco Angeli, Milano, 2005.

[2] Transport in figures. Statistical Pocketbook 2013; http://ec.europa.eu /transport/facts-fundings/statistics/pocketbook-2013_en.htm, 2013.

[3] Meersman, H. \& Van de Voorde, E., The Relationship between economic activity and freight transport (Chapter 2), Freight Transport Modelling, Emerald group publishing limited, pp. 17-44, 2013.

[4] White paper 2011. Roadmap to a Single European Transport Area Towards a competitive and resource efficient transport system, http://eurlex.europa.eu/LexUriServ/LexUriServ.do?uri=COM:2011:0144: FIN:IT:PDF, 2011.

[5] Conto Nazionale delle Infrastrutture e dei trasporti, Ministero degli interni (MIT), http://www.mit.gov.it/mit/mop_all.php?p_id=12558, 2010.

[6] Giordano, R., Gli scenari economici del Piano della Logistica. Sistemi di Logistica, 4, Giordano Editore, pp. 7-16, 2010.

[7] Piano nazionale della logistica 2012-2020, Bozza finale. Ministero delle infrastrutture e dei trasporti (MIT); http://www.mit.gov.it/mit /mop_all.php?p_id=12968, 2012.

[8] Russo, F. \& Musolino, G., Geographic factors affecting the presence of transhipment service in a regional maritime container markets. Geographical Analysis, 45 (1), pp. 90-102, 2013.

[9] Russo, F., Musolino, G. \& Assumma, V., An integrated procedure to estimate demand flows of maritime container transport at international scale. International Journal of Shipping and Transport Logistics, 6(2), pp. 112-132, 2014.

[10] Cartenì, A. \& Russo, F., A tour-based model for the simulation of a distributive freight system; in The Expanding Sphere of Travel Behaviour 
Research; selected papers from the 11th International Conference Travel Behaviour Research; Ryuichi Kitamura, T. Yoshii (Eds.), Emerald Group Publishing Limited, Bingley, Bingley UK, 2009.

[11] Quattrone, A. \& Vitetta, A., Random and fuzzy utility models for road route choice. Transportation Research Part E: Logistics and Transportation Review, 47 (6), pp. 1126-1139, 2011.

[12] Russo, F., Freight Transport Modelling. Modeling Behavioral Aspects of Urban Freight movements (Chapter 18), Emerald Group Publishing Limited, pp. 353-375, 2013.

[13] Russo, F., Comi, A., Measures for sustainable freight transportation at urban scale: Expected goals and tested results in Europe. Journal of Urban Planning and Development, 137(2), pp. 142-152, 2011.

[14] Polimeni, A., Vitetta, A., Vehicle routing in urban areas: An optimal approach with cost function calibration. Transportmetrica B: Transport Dynamics, 2 (1), pp. 1-19, 2014.

[15] Russo, F. \& Quattrone, A., ITS Sistemi di trasporto intelligenti. Elementi di base e applicazioni operative per il trasporto privato, per il trasporto pubblico, per il trasporto merci e la logistica, Franco Angeli, Milano, 2010.

[16] Programma PIL - Piattaforma Integrata della Logistica, http://www.pimex2013.eu/index.php?option $=$ com_docman\&task $=$ doc_download\&gid $=193$ \&Itemid=166\&lang=it, Levi, 2012.

[17] Almaviva http://www.almavivaitalia.it/wps/wcm/connect/4452968044 baed46b94cb9b6f4c749b2/Dossier_garaFerrovie.pdf?MOD=AJPERES,20 12.

[18] Agenda Digitale Italiana (ADI), http://www.agendadigitale.it/ agenda_digitale/images/documenti/progetto_uirnet_digitalizzazione_logist ica_per_guidare_crescita.pdf, 2012.

[19] De Dominicis, R., Quattrone, A. \& Russo, F., National freight multimodal transport system: the Italian project for the ITS integration (Chapter 27), Computers in Railways XIII, Brebbia, C.A. (ed), WIT Press, 2012.

[20] Directorate-General for Mobility and Transport (DGMT), http://www.transportresearch.info/Upload/Documents/201007/20100708 112138_82772_TRS\%20Rail\%20Transport.pdf, 2010.

[21] Cross-Border Information Technology (CroBIT), http://www.CroBIT.org /downloads/CroBIT_Del0erable_D3 final.pdf, 2003.

[22] Consorzio Armatori per la Ricerca (CONSAR), http://www.consar.net, 2012.

[23] Rete Autostrade del Mare (RAM), http://www.ramspa.it, 2012.

[24] Access, the Elsag Datamat solution for motorways of the sea (ELSAG DATAMAT), http://www.elsagdatamat.eu/PDF/Trasporti/Dangerous Goods ManagementSolutions.pdf, 2009. 